of multiplicity 2 have only two prime factors.* Hence we have to consider the two cases $m=4, m=3$.

When $m=4$ it is easy by inequality (3) to show that $p_{2}=3$ and $p_{3}=5$ or 7 and also to restrict the values of $p_{4}$ and $p_{5}$. Then by the help of the lemma applied to expressions of the form $p^{a+1}-1$ the values of the exponents $a$ in (1) may be restricted. Then by an examination of the remaining possibilities I have found that equation (2) is never possible when $p_{3}=7$. On the other hand, when $p_{3}=5$, there are three cases when (2) is satisfied; and consequently three multiply perfect numbers of multiplicity 4 as follows: $2^{3} \cdot 3^{2} \cdot 5 \cdot 7 \cdot 13$, $2^{9} \cdot 3^{3} \cdot 5 \cdot 11 \cdot 31,2^{7} \cdot 3^{3} \cdot 5^{2} \cdot 17 \cdot 31$.

For $m=3$ a similar discussion restricts $p_{2}$ to have the value 3 or 5 . When $p_{2}=5$ equation (2) is impossible, as is shown again by examining the possibilities for $p_{3}, p_{4}, p_{5}$ and the exponents. When $p_{2}=3$ there is only one set of values satisfying $(2)$, and these give a perfect number $2^{13} \cdot 3 \cdot 11 \cdot 43 \cdot 127$, of multiplicity 3.

The results arrived at may be stated thus :

The even multiply perfect numbers of only five different prime factors are the following: $2^{3} \cdot 3^{2} \cdot 5 \cdot 7 \cdot 13,2^{9} \cdot 3^{3} \cdot 5 \cdot 11 \cdot 31$, $2^{7} \cdot 3^{3} \cdot 5^{2} \cdot 17 \cdot 31$ of multiplicity 4 ; and $2^{13} \cdot 3 \cdot 11 \cdot 43 \cdot 127$ of multiplicity 3.

All these numbers are included in the table published in the BulletiN, volume 13, pages 385-386. A misprint occurs in the table : 23569921 for 23569920.

alabama Presbyterian College,

ANNiston, Ala.

\title{
THE FOURTH INTERNATIONAL CONGRESS OF MATHEMATICIANS: SECTIONAL MEETINGS.
}

THE several sections of the Rome Congress had their first meetings on Tuesday morning, April 7. For each section one or more chairmen had been appointed to open the session, but at each the presiding officer was elected for the following day. In general those who opened the sessions merely welcomed the members and asked for nominations for president for that day. In each section a secretary was appointed who kept a

\footnotetext{
* Carmichael, l. c., p. 150.
} 
full record of the proceedings. After the presentation of each paper, the secretary of the section asked the author to write a brief abstract. Through the kindness of the general secretary, Professor Castelnuovo, the reporter was furnished a copy of these abstracts, a liberal translation of which is given below. In general no abstracts were obtained for the papers presented by title; two others are also missing, viz., Professor Lamb's and Professor Capelli's. All the abstracts were to have been published in the "Bulletino" which was issued each morning, but owing to the difficulty of preparing them properly in so short a time this plan was not carried out. All papers and reports will be published in the Atti del Congresso, which is being prepared as rapidly as possible.

\section{Section I. Analysis.}

The section was opened by Professor Arzelà; the following acted as chairmen at different meetings : Jordan, Gordan, Forsyth, Pascal, E. H. Moore. The following papers were presented (to avoid repetition the abstracts immediately follow the titles) :

GoRdan (Erlangen): "Die Auflösung der allgemeinen Gleichung 6ten Grades."

As principal result, the author proves that the equation of Professor Gerbaldi is the normal form of the equation of the sixth degree.

Zermelo (Göttingen) : “ Über die Grundlagen der Arithmetik und Analysis."

From a new definition of infinite set are deduced the fundamental properties of the finite numbers, and in particular the principle of complete induction.

Borel (Paris) : "Sur les principes de la théorie des ensembles."

The author concludes that our exact notions of the power of a set do not come from anything else than the observations: there are enumerable sets and non-enumerable sets, this last definition being purely negative.

RIEsz (Budapest) : "Stetigkeitsbegriff und abstrakte Mengenlehre."

For the consideration of the so-called properties of continuity 
of distinct and concrete varieties the author introduces the concepts of type of condensation and type of concatenation. These concepts form the foundations of a general theory of continuous varieties. Some problems of such a theory were also indicated.

Frizell (Cambridge, Mass.): “Die Mächtigkeit des Kontinuums."

First there is taken from the continuum a set consisting of those numbers in whose development in partial fractions every natural number appears only once. Then those sets of numbers were considered which are obtained in an analogous manner, admitting that single digits may be repeated or omitted. The sets in which an infinite number of digits are wanting are obtained as limiting cases. Finally the order of the continuum was determined.

KoEBE (Göttingen): “Über ein allgemeines Uniformisierungsprinzip."

After some historic observations, the author passed to the consideration of his most recent articles published in the Göttinger Nachrichten on the uniformization of algebraic or analytic curves by means of automorphic functions; he considered then the recent memoir of Poincaré, "Sur l'uniformisation des fonctions analytiques" (Acta Mathematica, volume 31) in order to characterize the analogous general problems which present themselves in consideration of groups of imaginary substitutions, and their solution.

Boutroux (Paris): "Sur l'inversion des fonctions entières."

The author discussed the relation of the problem to the general problem of the uniformization of the different mechanisms of permutations presented by the inverse of the integral functions, and showed how the general solution of the problem presents itself.

Petrovitch (Belgrade): "Une classe remarquable de séries entières."

The author seeks the necessary and sufficient condition in order that a Maclaurin series have the property that all its zeros are real, and that the same be true of any polynomial formed of any number of terms at the beginning of the series. He gave some general properties of such a series, and established the ex- 
istence and showed the formation of such a series in which any coefficient reaches its greatest possible maximum value. He gave also some properties of the transcendental function formed by this series.

Pincherle (Bologna): "Alcune spigolature nel campo delle funzioni determinanti."

Having recalled the definition, the history and the properties of determinants, the author put the infinite order of the generator in relation with the singularity of the determinant, and made an application to Dirichlet's series and to the creation of a succession of operations corresponding to the succession of the known functions typical for the order of infinity.

Young (Cambridge): "On some applications of semi-continuous functions."

The author gave an account of the application which he has made of semi-continuous functions, 1) to the conditions of continuity, 2) to the theory of integration, 3) to the theory of measure, 4) to the discussion of the distinction of right and left, 5) to the theory of uniform convergence and of divergence of series. He added an account of its most recent applications to the theory of oscillating series, in which the concept of point of inferior and superior semi-continuity has necessarily the leading rôle.

Laura Pisatr (Rome): "Saggio di una teoria sintetica delle funzioni di variabile complessa."

Doctor Pisati died March 30, and her paper was presented by title by Professor Marcolongo; it will appear in the "Atti del Congresso."

Hadamard (Paris): "Sur l'application d'une méthode du calcul des variations."

The method indicated by the author in the Comptes Rendus (December, 1906) to demonstrate the existence of solutions of a problem in the calculus of variations does not present any particular difficulties in the case of the isoperimetric problems or in the case in which the integral is taken in the parametric form.

Schidesinger (Kolozswar): "Sur quelques problèmes paramétriques de la théorie des équations différentielles linéaires." The author spoke of some problems which one encounters in studying the relations between the fundamental substitutions 
and the parameters on which the coefficients depend in the theory of linear differential equations.

RŁmoundos (Athens): "Sur les zéros des intégrales d'une classe d'équations différentielles."

The author made use of a method of elimination which he used in his dissertation (Sur les zéros d'une classe de fonctions transcendantes, Paris, 1906) in order to extend a classic theorem of Picard to multiform functions of a finite number $n$ of branches. He established a theorem analogous to that of his dissertation and considered the integrals of a very extended class of differential equations. The integrals of these equations either satisfy the above theorem or possess another property inherent in the existence of more integrals common to the differential equation considered and to those which express the derivatives $u^{\prime}, u^{\prime \prime}$ in functions of $u$.

Prck (Prag) : “Über die Differentialgleichung der hypergeometrischen Funktion."

The author developed in a new aspect the general theory of the hypergeometric differential equation, considering in a more extended manner the case of equations of lower orders and having three singular points.

SoLtykow (Krakow): "Sur l'existence des intégrales complètes de $\mathrm{S}$. Lie et le perfectionnement de la méthode de Jacobi dans la théorie des équations aux dérivées partielles." The author gives the general form of the partial differential equation which admits the complete integral of Lie of any order whatever. He makes some improvements on the method of Jacobi-Mayer, showing how the modifications thus introduced do not destroy the symmetry of the calculations of Jacobi. Every differential system of the characteristics takes the form of a canonical system of total differential equations.

LALESco (Bucarest): "Sur les solutions analytiques de l'équation $\partial^{2} Z / \partial x^{2}=\partial Z / \partial y . "$

It was shown that the solutions of the equation indicated which are analytic in a point are integral functions in $Z$ of order at most equal to two, and that this property is characteristic. There results a rapid method for determining the order of certain integral functions and a general result is suggested. From this result Fourier's formula for all the analytic solu- 
tions of the equation considered can be established. Analogous results are obtained for other equations.

Volterra (Rome) : “ Sopra il metodo delle imagini nelle equazioni del tipo iperbolico."

The author started from the formulas given by him in the Acta Mathematica, volume 18, for the integration of the fundamental equations of the hyperbolic type. He recalled that he had given the method of images in particular cases in his Stockholm lectures and finally showed that the principle of images can be considered in all its generality in the case of equations of the hyperbolic type, exhibiting the peculiar character which the method of successive images assumes, in virtue of the influence which the real characteristic cones exert.

ZERvos (Athens): "Sur la correspondance entre la théorie d'intégration des équations aux dérivées partielles du premier ordre et l'intégration des systèmes de Monge."

The author showed how in certain particular cases the theory of the integration of partial differential equations can be made to correspond to the theory of the integration of a system of Monge.

Moore (Chicago): "On a form of general analysis with applications to linear differential and integral equations."

Two principles of generalization were discussed, one by means of abstraction and the other by means of the addition of a parameter. These were enunciated and illustrated by means of the general theories, 1) of the linear integral equation, 2) of the linear differential equation. These general theories have the form of systems of deductive logic, and their special form suggests, as probably useful, the following scheme of general analysis. One branch of general analysis (of the form in question) is a system of deductive logic which is referred to the system of real numbers and comprises one or more variables, in whose character and field of validity nothing is fixed except by means of postulates regarding one or more symbols not defined, which represent classes of functions of those variables.

Fredholm (Stockholm): "Les intégrales de Fourier et la théorie des équations intégrales linéaires."

The author calls attention to the fact that a class of integral equations of the second kind exists whose solution is a polyform 
function from which are derived all the integral equations of the first kind which are solved in the manner of the integrals of Fourier.

D'Adhémar (Lille): "Sur les équations intégrales de Volterra."

The author showed the necessity for introducing the partifinite of the infinite integrals in the problem of Volterra. $\mathrm{He}$ treated a problem a little more general than that of Volterra and Lalesco by the method of successive approximations and studied the analytic nature of the solutions.

Orlando (Rome): "Sulla risoluzione delle equazioni integrali."

The author showed a method of solving integral equations with a polynomial nucleus and by means of the method of successive approximations passed to the general case. He also considered equations which contain the derivative of the unknown function.

Pascal (Naples): "Sulla nuova teoria delle forme differenziali di ordine e grado qualunque."

This gave a summary of all the principal results which the author had obtained for this theory up to the present time.

De Donder (Brussels): "Sur les invariants intégraux." (Presented by title.)

Stéphanos (Athens): "Sur une extension de la théorie des covariants et invariants de formes binaires."

The author considered the expression $\sigma\left(y, y^{\prime}, y^{\prime \prime} \ldots\right)$, where $y$ denotes any function whatever and $y^{\prime}, y^{\prime \prime}$ its successive derivatives, having the property of satisfying all differential equations

$$
m y \frac{\partial \sigma}{\partial y^{\prime}}+(m-1) y \frac{\partial \sigma}{\partial y^{\prime \prime}}+\cdots+(m-\rho+1) y \frac{\partial \sigma}{\partial y^{(\rho)}}+\cdots=0 .
$$

These expressions are generalizations of the covariants of binary forms. The author gave different properties of such expressions and showed their importance in the solution of different algebraic problems.

Montessus (Lille): "Sur les relations de recurrence à trois termes."

The author refers to the solution of the problem of analytic 
continuation which the theory of continuous functions gives, and seeks to demonstrate Poincaré's theorem by substituting a relation of recurrence with constant coefficients for the relation of recurrence with variable coefficients.

Pucciano (Demetrio Corace): "Contributo alla critica di alcune questioni che si riattaccano all'equazione differenziale di Laplace."

The author demonstrated : 1) That the conditions sufficient for asserting the integrability of the partial differential equation of the first order $\partial v / \partial x+\partial v / \partial y=f(x, y)$ are also sufficient for the integration of the differential equation of Poisson $\Delta_{2} u=$ $h(x, y)$ provided that $v$ is capable of definite integration in a domain $\sigma$ about the point $(x, y)$ and provided that in the same domain $\partial^{2} v / \partial x \partial y$ and $\partial^{2} v / \partial y \partial x$ exist, are equal, and capable of integration. 2) If the function $g_{s}$ of the arc of a closed line is such that the logarithmic potential $\int g_{s} \log 1 / r d s$ be transformable, in the region outside, into a logarithmic potential $\int n_{s} \frac{\partial \log 1 / r}{\partial u} d s$, there exists, in the region inside, the harmonic function which has on the boundary the normal derivative equal to $g_{s}$.

Capelur (Naples): "Sopra i coefficienti degli sviluppi delle funzioni algebriche."

Nicoletri (Pisa): "Riduzione a forma canonica di un fascio di forme bilineari e quadratiche."

The author gave the fundamental lines of a rational demonstration of the theorem of Weierstrass on the equivalence of two pencils of bilinear forms, whose determinant is not identically zero, considering particularly the case of pencils of symmetric forms.

Fubini (Genoa) : "Sulla teoria dei gruppi discontinui."

After a summary of the results of Poincare, the author gave some generalizations of groups which transform any region whatever into itself, of groups of conformal transformations, and finally sketched a method which in some cases may serve to recognize the discontinuity of linear groups in any number of variables. 
Dickson (Chicago): "On the last theorem of Fermat" (presented by title).

Levi, B. (Cagliari): "Sopra la equazione indeterminata del $3^{\circ}$ grado."

The author occupied himself with the determination of the rational solutions of the indeterminate equation of the third degree by means of rational processes, starting from known rational solutions : particularly with the case in which such processes reproduce the solutions with which one started. He defines the principal cases and finally connects the problem with that of the solution, in numbers rational with respect to the modulus of the equation, of the division of the period of the elliptic sine.

Fratlini (Rome) : "La nozione di indice e l'analisi indeterminata dei polinomi interi."

After a brief introduction, the author separated the irrational binomials $E+F \sqrt{D}$ (where $E, F$ are rational functions) into hyperbolic and elliptic, and defined the index of an irrational binomial, giving a rule for its determination. He concluded by giving some applications.

Severini (Catania): "Sulle successioni infinite di funzioni analitiche."

Having recalled the researches made on the subject in the direction of Cauchy and Riemann, the author passed to the consideration of it from the point of view of the theory of Weierstrass, in the way, that is, of making the property of the given succession of analytic functions depend on the conditions given for the elements which determine them.

Zaremba (Cracovie): "Sur le principe de Dirichlet."

The author substitutes for the problem of Dirichlet another more general problem which he calls the transformed problem and shows that the theory of Dirichlet's principle and of allied questions result very simply from the theory of the transformed problem.

Boggro (Turin): "Sulla risoluzione di una classe di equazioni algebriche che si presentano nella matematica finanziaria."

Professor Boggio calls the attention of analysts to the solution of those algebraic equations in which all the coefficients 
are positive, except the known term which is negative. Such equations are met in the general theory of loans; and the determination of the return from a loan reduces itself exactly to finding the unique positive root of equations of this kind.

\section{SeCtion II. Geometry.}

The section was opened by Segre; the following acting as chairmen at different meetings : Zeuthen, Darboux, d'Ovidio, Schur.

The following papers were presented :

Andrade (Besançon): "Le théorème de Ampère-Stokes et le postulatum d'Euclide."

If one considers a non-euclidean translation along an infinitesimal closed curve which is the boundary of an element of area as equivalent to a normal rotation proportional to the area, there follows from this an intuitive demonstration of Archimedes's theorem on the equilibrium of pressure distributed uniformly on a closed surface. This demonstration suggests the immediate extension of the theorem of Ampère-Stokes to non-euclidean space.

One deduces from it that the non-euclidean is the only space which admits an orthogonal net of "dallage," and establishes that the vectorial element $d s^{2}=d x^{2}+d y^{2}+d z^{2}$ is characteristic for euclidean space.

The result is not new but the connection with the theorem of Ampère-Stokes is interesting.

VARICAK (Agram) : "Beitrag zur nicht-euklidischen analytischen Geometrie."

Starting from the translation of Halsted relative to the geometry of Bolyai-Lobachevsky and from a work by Liebmann on the same subject, the author gave some applications of the calculus in the analytic geometry of Lobachevsky.

ZeUTHeN (Kopenhagen) : “Un esempio di una correspondenza senza Wertigkeit."

The author spoke of the determination of pinch points of the ruled surface generated by the lines which cut a given line.

Montesano (Naples): "Sui complessi bilineari di coniche nello spazio."

The author gave an account of some researches begun in 
1888 , and made mention of the studies of Humbert; he gave the common genesis of the complexes which he has studied.

SEverI (Padua): "Di alcuni recenti risultati sulla geometria algebrica e di qualche problema ad esso collegato."

Having recalled the known results relative to the simple integrals belonging to an algebraic surface, the author considers the cause of irregularity of a linear system which is connected with the irregularity of the surface, for the purpose of finding a neat determination of the cause of the irregularity noted. He defines on an algebraic curve of the surface the reduced canonical series and gives the geometric genesis by demonstrating that the independent curves $C+C^{\prime}$ which pass through the base points and through the double movable points of the curve of a pencil $|C|$ are $p_{g}-p_{a}$ in number, $\left|C^{\prime}\right|$ being the system adjoint to $|C|$ and $p_{g}-p_{a}$ being the irregularity of the surface. These curves $C+C^{\prime}$ cut a curve $C$, outside of the base points, in the reduced canonical series.

The preceding result is obtained as a consequence of the following theorem of which the demonstration was sketched:

The necessary and sufficient condition that an abelian integral of the second (or of the first) kind belonging to a curve whose coefficients contain rational parameters have periods independent of the parameters is that the integral considered should not become of the third kind for any particular value of these parameters.

Bagnera (Messina): "Sopra le equazioni algebriche $f(x, y, z)=0$ che si possono risolvere con $x, y, z$, funzioni meromorfe quadruplamente periodiche di due parametri."

Given the table of primitive periods

$$
\left|\begin{array}{cccc}
a_{1} & a_{2} & a_{3} & a_{4} \\
a_{1}^{\prime} & a_{2}^{\prime} & a_{3}^{\prime} & a_{4}^{\prime}
\end{array}\right|
$$

for the quadruply periodic functions of two parameters $u, v$

$$
x=p_{1}(u, v), \quad y=p_{2}(u, v), \quad z=p_{3}(u, v),
$$

and supposing that to every point $(x, y, z)$ of the surface corresponds a pair of values $(u, v)$, one can consider the surface as representing the groups of an involution on an hyperelliptic surface of the given table. The linear substitutions 
$u^{\prime}=a u+b v+c, v^{\prime}=a^{\prime} u+b^{\prime} v+c^{\prime}$ which transform a point $(u, v)$ into a point $\left(u^{\prime}, v^{\prime}\right)$ belonging to the same group with $(u, v)$ form a group.

De Franchis (Parma): " Intorno alle superficie regolari di genere uno che ammettono una rappresentazione parametrica mediante funzioni iperellittiche di due argomenti."

This was an exposition of the methods which serve for the effective construction of the regular hyperelliptic surfaces of genus $t$. The criteria were also given which serve to characterize these surfaces.

Radus (Budapest): “ Über die Wendetangentenebenen von Raumkurven."

The author gave some criteria for the existence of inflexional tangent planes for twisted curves in ordinary space and space of higher dimensions.

Bianchi (Pisa): "Sulle trasformazioni di Darboux della superficie di area minima."

The transformations of minimal surfaces are those given by Darboux in volume 3 of his Théorie des Surfaces (page 441). From a given surface $S$ of minimum area, by the transformation $D$ of Darboux, we obtain a simple infinity of such surfaces. These transformations applied to real surfaces give imaginary surfaces.

These transformations of Darboux preserve the lines of curvature and the minimum lines. When they are compared with those (real) transformations of minimal surfaces which result from the theorem of Guichard on the deformation of a paraboloid of revolution, we observe that every such transformation of Guichard can be resolved into two conjugate imaginary transformations of Darboux.

Four classes of applicable surfaces depending on minimal surfaces were considered, viz.:

(a) The evolutes of the minimal surfaces.

(b) The deformed surfaces of the paraboloid of revolution.

$(c, d)$ The surfaces applicable to the two paraboloids of Darboux with a generator tangent to the circle at infinity.

For the surfaces of each class the transformations of Darboux give rise to a line congruence $W$ whose two focal surfaces belong to the class considered.

The transformations thus obtained for the deformed surfaces 
of the paraboloids are only a particular case of the transformations for the surfaces applicable on the general quadric, of which a hint is given by enunciating a more general problem whose solution seems desirable.

Panelli (Rome) : "Sopra un carattere delle varietà algebriche a tre dimensioni."

Given in a variety $V_{3}$ a net $|S|$ of surfaces $S$ determined by a simple base curve of genus $\pi$ and by a number $P_{0}$ of base points, also simple for each surface $S$. Call $P$ the arithmetic genus of the (variable) curve of intersection of two surfaces and $P_{0}$ the arithmetic genus of a surface $S$. The expression

$$
I_{1}=* g+P_{0}-g P_{1}-36 P_{0}+(\pi-1)-28,
$$

in which $g$ denotes the genus of the Jacobian of the given net, does not depend upon the selection of the net and for this reason constitutes a relative invariant of the variety.

The invariant $I_{1}$ and Segre's invariant $I_{0}$ of the same variety $V_{3}$ are connected with the arithmetic genus $\pi_{\theta}$ by the relation

$$
48 \pi_{\theta}-56=2 I_{1}-I_{0} .
$$

Between the invariants $I_{0}, I_{1}$ and $\Omega$ the following relation exists :

$$
2 L\left(\Omega_{0}-\Omega_{1}+\Omega_{2}\right)=2 I_{1}-I_{0}-42 .
$$

The invariant $I_{1}$ is applied to the solution of problems in enumerative geometry concerning the nets $\Omega$ of surfaces contained in a $V_{3}$.

Dingeldey (Darmstadt) : “Zur Erzengung der Kegelschnitte nach Braikenridge und Maclaurin."

The author showed how to classify the elements which serve for the generation of the conic sections according to Braikenridge and Maclaurin, in order to generate the hyperbola and the parabola in the simplest manner possible. Also the dual generation, according to which these curves appear as the envelope of their tangents, was recalled.

Finsterbusch (Zwickau): "Über eine Erweiterung eines Schliessungsproblems von J. Steiner und ihre Beziehung zur Gauss'schen Theorie zentrierter Linsensysteme."

Two extensions of the problem of Steiner were given : The 
first extends the theorem of Steiner to the cyclides of a pencil and reaches the final form

$$
\frac{u_{2}}{Z_{n_{1}}}+\frac{u_{2}}{Z_{n_{2}}}=\frac{1}{2}-\frac{r}{Z}
$$

which for $r=0, Z=1$ gives Steiner's formula. The second extension consists of a general theorem which presents an analogon to the theory of central optical systems.

GallucCI (Naples) : "Su la configurazione armonica."

The 24 points and the 24 planes of the configuration can be indicated by means of the 24 permutations of 4 elements and the properties of the configuration result immediately.

BRÜCKNER (Bautzen): “Bemerkung zur Morphologie der aussergewöhnlichen Polyeder erläutert durch die Sechsfläche."

Indicating on the blackboard the images of the polyhedrons with six double or single faces, the principles of the division of the irregular polyhedrons into classes and the principal methods for the generation of these forms were explained.

Brouwer (Amsterdam): "Une théorie des groupes finis et continus indépendante des axiomes de Lie."

In this paper the theory of Lie's groups is founded on the existence of certain derivatives of functions determining the group, then the existence of the infinitesimal transformations is deduced from this. The biuniform and continuous representation of the groups on a continuum of $P$ dimensions was shown and from this the groups of the varieties of one and two dimensions were determined.

Tzitzeika (Bucarest): "Sur une nouvelle classe de surfaces." Starting from a system of partial differential equations which the coordinates of a point of a surface referred to general curvilinear coordinates satisfy, it is found that the surfaces for which the ratio of the total curvature to the fourth power of the distance from the origin to the tangent plane remains constant, are the simplest surfaces which present themselves in this theory.

Pfeiffer (Kiev): "Des développements des fonctions algébriques de deux variables indepéndantes en séries entières des variables indépendantes."

The condition was found for the existence of algebraic func- 
tions of two independent variables in series of powers of the independent variables in uniplanar and biplanar points.

\section{Section III A. Mechanics and Mathematical Physics.}

The section was opened by Professor Pizzetti ; the presidents of the various sessions were Professors Volterra, Darwin, Liapounoff, Wangerin, Luiggi. The programme contained the following papers :

DARwIN (Cambridge) : "The rigidity of the earth."

According to the theory of Lord Kelvin, if the earth were as rigid as steel the oceanic tides would have an amplitude two thirds of that which they would have on a globe absolutely rigid. The author examined the grounds of this conclusion, compared them with the older theory of Laplace, and made various corrections by means of the investigations of Rayleigh, Paschwitz, Ehlert, Cortazzi and Hecker. The conclusion is that the ratio is about .6, that the coefficient of elasticity is different in different directions, and that the solid earth rises and falls about $17 \mathrm{~cm}$. by the action of the tides.

LAMB (Manchester): "The flexure of narrow beams."

LAURICELla (Catania): "Sull'equazioni $\Delta^{2 n} V=0$ e su alcune estensioni dell'equazioni dell' elasticità."

The method indicated by Professor Lauricella to demonstrate the possibility of solving the problem of the boundary values for the equation $\Delta^{2 n} V=0$ in any number of variables is valid also for the equation $D^{2 n} V=0$ and in particular for the equation $D^{6} V=0$.

For this purpose a theorem of equivalence is demonstrated under which the problem is reduced to that of finding the solutions of a system of equations in more unknown functions which take given values at the boundary, a system in fact analogous to that of the equations of elasticity. For this system of equations he introduces the concept of pseudo-hypertensions, which are integrals analogous to double distribution, and which lead to the consideration of a system of functional equations to which one can apply the known results of Fredholm. In this manner he demonstrates the existence theorem for the problem stated above. 
Somigliana (Turin) : "Sulle deformazioni elastiche non regolari."

The author demonstrated first that elastic distorsions can exist satisfying the conditions established by Weingarten and not satisfying those of Volterra, and that such distorsions are possible also in bodies simply connected. Making use of a concept of Professor Morera, he announces a possible theory of the state of tension of "Prince Rupert's drops."

Abraham (Göttingen) : "Zur Theorie der Wirbelstrombremsen."

On the basis of the Electrodynamics of Hertz for bodies in motion, the field on the inside of a moving body was determined when that body was composed of iron or copper, which acts as a brake. The author investigated how far the dependence of the force on the velocity can be determined theoretically.

Andrade (Besançon): "Sur une nouvelle méthode de mesure des frottements."

The measure of the coefficient of friction is made by the author by means of the study of the extension of the movement of an oscillating wheel in which the friction comes from the action applied on the two cylindrical supports of different radii. The resistance of the air is eliminated and thus also is eliminated the friction of rotation, the measurements being made on supports of different radii.

KoRN (Vienna): “Über die universellen Schwingungen der

Materie mit Anwendungen auf die Theorie der Gravitation und der intramolekularen Kräfte."

After a brief exposition of the fundamental principles of universal vibrations - vibrations of the material particle slightly compressible, immersed in a half compressible fluid - the vibration of pulsation necessary for the explanation of gravitation as the fundamental vibration of the universal vibration was explained; and for electrons which must be considered also as pulsating particles a mechanical difference from gravitating particles was found, this difference being expressed by substituting Coulomb's law in place of Newton's.

Levi-Crvita (Padua): "Sull' espressioni assintotiche dei potenziali ritardati."

A retarded potential $v$, when the point $P$ which caused it is 
moved, depends on the velocity of the movement. It is advantageous to consider the position of the body at an earlier time, but there is no advantage in doing so when the velocity of propagation increases without limit and when the trajectory of $P$ passes through its position at the actual time considered. The paper is concerned with the development of the retarded potential in the second limiting case. The concept of Abraham of the quasi-stationary condition finds its mathematical expression in this asymptotic development.

Garbasso (Genoa): "La luce bianca."

The author studied the normal spectrum of a damped vibration. In accord with Zelinder's experiments and in opposition to the theory of Carvallo, he succeeded in establishing that the spectrum considered is continuous. The method consisted in decomposing the function $e^{-a t} \sin b t$ into a sum of undamped harmonics, but limited to a finite interval of time.

Greenhill (London): "Geometry of the motion of the spinning top."

This was a method for designing a family of curves, hodographs of the Poinsot herpolhode, employing the focal ellipse of a deformable hyperboloid and a tangent generating line for the determination of the apsidal angle and of the limiting inclinations of the axis.

Sommerfeld (Munich) : "Beitrag zur Erklärung der turbulenten Flüssigkeitsbewegung."

The gap which seems to exist between practical hydraulics and theoretical hydrodynamics has been repeatedly observed and deplored. It is known that Osborne Reynolds succeeded in crossing this abyss by introducing the notion of stability. $\mathrm{He}$ brought to light the existence of a critical point for the velocity, rendering possible the qualitative law with dimensional considerations, and determined the numerical value by experimental means. Above the critical point the movement is unstable and below it is stable.

These ideas have been notably simplified and extended by the work of Lorentz, who also recognized that the case of the flow between two concentric cylinders and between two plane walls, studied experimentally by Conetta is still simpler than the typical problem of the flow in a cylindrical tube, originally 
taken for consideration. The research of Professor Sommerfeld relates precisely to this simpler case of Lorentz-Conetta and treats it by the classic method of small oscillations.

The general solution of the problem can be given without difficulty; the expression is found by means of the integrals of cylindrical functions. The condition of instability is characterized by a certain transcendental equation. The discussion of the equation, in the simple case of small velocity, leads to certain results already noticed by Lord Rayleigh.

BoGgro (Turin) : "Sopra alcuni teoremi di fisica matematica."

The author gave a direct method for demonstrating that the integrals of the indefinite equations of numerous problems of mathematical physics, when considered as functions of the parameters which figure in the equations themselves, cannot depend on such parameters, but rather on the simple poles.

BocCARDI (Turin) : "Sopra una nuova equazione nelle osservazioni dei passaggi."

Professor Boccardi has made a long series of observations of right ascension and has established that, reduced to the medial equinox, they present oscillations according to the state of the sky, in the sense that the right ascensions for observations with no wind and with sky entirely serene are smaller than those observed in bad conditions. He constructed a table of comparisons, which he called equations of transparency.

ANdRAde (Besançon): "La synchronisation par le fer doux."

The periodic synchronizing force does not exist with the use of soft iron, yet by Picard's method of approximation the theory can be extended to this case and also to that in which the viscous resistance is no longer exactly proportional to the velocity.

GENESE (Aberysthwyth): "The method of reciprocal polars applied to forces in space."

The note is an extension to space of a paper on reciprocation in statics, published in the Proceedings of the London Mathematical Society in 1886. As an illustration of the first note, the author demonstrates how a weight can be distributed on a closed curve in such a way as to put the centroid in any point whatever in the interior. He obtains the important result

$$
\int \frac{d s}{p^{2} \rho} x=0
$$


on each closed curve. He further showed how the fundamental formula of Grassmann is applied to the case in which $e / c$ is not equal to unity; coordinates not being necessary.

Macfarlane (Chatham): "On the square of Hamilton's delta." (Presented by title.)

Tedone (Genoa) : "Sopra il problema di Lamé."

Professor Tedone sought to give a complete solution of the problem of determining the triply orthogonal systems formed by the surfaces $q_{1}=$ const., $q_{2}=$ const., $q_{3}=$ const., such that two of these series of surfaces be surfaces of rotation about the same line in such a way that Laplace's equation have the simple solution of the form

$$
\operatorname{Pf}_{1}\left(q_{1}\right) f_{2}\left(q_{2}\right) f_{3}\left(q_{3}\right)
$$

$P$ being a given function.

Bryan (Upper Bangor, Wales): "Notes on the steering of automobiles and on the balancing of ships."

The connections commonly used in the steering of automobiles do not completely satisfy the geometric conditions to prevent lateral slipping. The problem here considered tends to this end. Considering the two front wheels, the locus of their gyrating center is a curve of order eight and the condition demanded is that the axis of the rear wheels be the asymptote of this curve.

Chemien has recently discussed the possibility of eliminating the rolling of a ship by means of a pendulum or a movable mass contained in a case filled with a viscous liquid. It is here shown that such a method gives rise to a system with two degrees of freedom. The oscillations are determined by an equation of degree 4 , and one must separate this equation into its quadratic factors in order to study the two oscillations. For this purpose one adopts the real root of the reducing cubic and approximates to this value for the case in which the mass of the pendulum is small compared with that of the ship. It is true that this arrangement becomes dangerous under certain circumstances.

Poynting (Birmingham): "The momentum of a beam of light."

Considering the energy of the incident and reflected waves 
when a perfectly reflecting surface is moved toward a plane pencil of waves, the author deduces the ordinary formula in which the pressure of radiation of the plane waves is equal to the energy of volume, with the limitation that the waves are of such a character that the energy of volume is inversely proportional to the square of the length of the wave. Supposing that the pressure of radiation is due to the momentum of the pencil, the author obtains a different expression for the pressure on a movable plane. The last concept suggests the existence of a tangential component when the pencil falls obliquely on an absorbing surface. The existence of such a tangential component is confirmed by the experiments of the author.

Kolossoff (Iuriev): "Sur le problème plan dans la théorie d'élasticité."

The problem leads to the integration of the differential equations

$$
\frac{\partial N_{1}}{\partial x}+\frac{\partial T}{\partial y}=0, \quad \frac{\partial N_{2}}{\partial y}+\frac{\partial T}{\partial x}=0, \quad \Delta_{2}\left(N_{1}+N_{2}\right)=0,
$$

in which

$$
\begin{gathered}
2 T=\alpha \frac{\partial\left(N_{1}+N_{2}\right)}{\partial y}-\beta \frac{\partial\left(N_{1}+N_{2}\right)}{\partial x}+\phi, \\
N_{1}-N_{2}=\beta \frac{\partial\left(N_{1}+N_{2}\right)}{\partial y}+\alpha \frac{\partial\left(N_{1}+N_{2}\right)}{\partial x}+\psi,
\end{gathered}
$$

$\phi$ and $\psi$ being two conjugate functions and $\alpha$ and $\beta$ satisfying the equations

$$
\frac{\partial \alpha}{\partial x}-\frac{\partial \beta}{\partial y}=-1, \quad \frac{\partial \alpha}{\partial y}+\frac{\partial \beta}{\partial x}=0 .
$$

Various cases can be treated in a similar manner and the method indicated gives the mode of transforming the solutions obtained and of finding some new ones.

Section III $B$. Actuarial Science and Engineering.

The section was opened by Professor Toja. Presidents : Toja, Quiquet.

ToJA (Florence) : “Alcune considerazioni sui rapporti tra le matematiche e la scienza attuariale."

The author considered the problems of actuarial science con- 
nected in greater part with mathematics, dwelling more especially on the concept and determination of probability a posteriori, from the perequation and from the analytical representation of an observed phenomenon. He then discussed the solution of three complex problems of the mathematical theory of pensions which furnish a good idea of actuarial devices.

QuiqueT (Paris) : "Sur une nouvelle application des jacobiens aux probabilités viagères."

The author explained that this paper is the result of his actuarial thesis (1892) and of the communication which he presented at the congress in New York (1903).

Poussin (Paris): "Sur l'application du graphicisme aux calculs d'assurance."

The paper of Poussin is intended to complete a paper published in 1904, in the Bulletin of the French actuaries. The case discussed is that of an endowment insurance with counter insurances. By opportune transformations the author succeeds in putting the analytic expression of the premium in such a form that it can be calculated graphically with appropriate wire polygons. An album containing the necessary tables for performing the various graphical processes was exhibited.

Elderton (London) : "A comparison of some curves used for graduating chance distribution."

In this paper the principal systems of curves of frequency studied by Pearson, Thiele, Charlier, Edgeworth, Bruns were exhibited. After having outlined the method of perequations of Pearson, the author applied equations of curves of form already known to practical cases relative to typical frequency.

Bohrmann (Wilmersdorf-Berlin) : “ Über die Grundlagen der Wahrscheinlichkeitsrechnung in ihrer Anwendung auf die Lebensversicherung."

Mr. Bohlmann forms a system of postulates from which theorems of the calculus of probability can be deduced logically. He examines the criteria of probability concerning the independence of events and demonstrates the sufficiency of the usual criterium. He formulates supplementary postulates necessary to define the survival functions of the mathematics of insurance and gives a relation between the survival functions of groups and those of single individuals. 
Borel (Paris): "Sur les applications du calcul des probabilites aux sciences biologiques."

It is desirable to make the same distinction in the science of biology as in mathematical physics between the two following questions :

(a) The investigation of the rigorous relations between abstract values.

(b) The study of the approximate relations between these abstract values and the concrete values furnished by experiments.

March (Paris) : “Une nouvelle statistique internationale de la population. Observation sur la comparaison et sur la terminologie des statistiques." (Read by Borel.)

De Helguero (Rome) : "Sulla rappresentazione analitica di alcune statistiche."

Observing that the methods proposed for the study of arithmetical statistics do not harmonize with the normal curve, the author gives some methods for a study in which they are considered as perturbations of the normal variables.

The principal hypothesis is that in which the equation

$$
y=\frac{y_{0}}{-\sigma \sqrt{2 \pi}}\left(1+\frac{\alpha}{\sigma}(x-b)\right) e^{-\frac{1}{\left(\frac{x-b}{\sigma}\right)^{2}}}
$$

is assumed ; the author has constructed some tables for the calculation of the parameters.

Lembourg (Brussels): "L'actuaire, sa fonction, les deux aspects de celle-ci."

The actuary, like the engineer, has need of mathematics : but the practice of his profession can render some contributions to mathematics itself. In fact, the actuary does not limit his function to the study of questions of insurance, but all fields which can be explored only by the aid of statistics are of interest to him.

The question presents two aspects - that previously given and this other: the mathematical spirit which he possesses causes him to introduce into the solutions of the financial questions a correctness and a rigor which result in good both for the insurer and the insured. 
GINI (—

The author spoke of the regularity of rare phenomena and proposed to demonstrate how the theoretic reason given by Bortkewitsch for a normal dispersion of the series of rare phenomena does not withstand criticism. He gave the results obtained from the measure of the regularity of some statistical series of rare phenomena relative to mortality.

Dawson (New York): "Necessary cautions in dealing with actuarial problems."

In the absence of the author the communication was read by title and copies of the printed paper were distributed.

Castell (Rome): "Sull'insegnamento della matematica attuariale e finanziaria nelle scuole professionali inferiori, medie, e superiori."

The paper more especially dealt with the work of the minister of agriculture, industry and commerce in Italy ; it proposed to promote the study of the applications of mathematics to questions of credit, foresight, and economy in the professional schools.

\section{Section IV. Philosophy, History and Teaching of Mathematics.}

Section opened by Professor Enriques. Presidents : Enriques, Loria, Vailati, Fehr, Zeuthen, Picard, Simon.

At the opening Professor Enriques delivered an address: "Matematica e filosofia."

He showed the development of the philosophic ideas dominant among reflecting mathematicians in regard to the conception which they form of real science. In the first period (cartesian) the cosmologic problem is accompanied by a metaphysical concept; after the newtonian systematization the problem of knowledge dominates (Kant) ; in our days the critical spirit tending to a rigorous foundation of mathematics is the principal characteristic. These three principles correspond to a purification and abstraction of mathematical theory which combine, in origin, the elements of experience, intuition, and logic. In fact from a statical point of view the complete mathematical theory tends now to a formal orientation which satisfies certain esthetic and economic demands. 
But side by side with this point of view is the dynamical view of the science of the investigators who regard the theory in formation. Psychological problems accompany this view. The duality between the logical and psychological tendencies of reflecting mathematicians today corresponds exactly to the different ideals which these thinkers form of science, as a complete organism or a formative process.

Hessenberg (Bonn) : "Numeri ed intuizioni."

The fundamental theories of numbers are essentially theories of type $\omega$. This is an object of logic, but the construction of their elements results from intuition, since these elements are logically irreducible. The case is perfectly analogous to that of geometry in which the system of relations is the logical object but the elements themselves are not.

Boutroux (Paris): “Sur la relation de l'algèbre à l'analyse mathématique."

Historically mathematical analysis is an extension of algebra. Analysis and algebra were synonymous terms for Newton, Euler, and Lagrange, the former differing from the latter in so far as it implies infinite operations; thus a long tradition leads us to consider analysis as the study of convergent algebraic expressions. This opinion does not now seem to be tenable. Analysis is not a construction ; it is the effort we make to analyze and to translate mathematical laws into the language of algebra. Algebra is only an instrument of analysis.

ITELsoN (Berlin) : "Logik und Mathematik."

We can determine the relation between logic and mathematics only when we are given a definition of one or the other. Logic is not, as ordinarily defined, the science of thought; it is, when we actually consider it, the science of things in general.

The author spoke also of the calculus of logic, of the duality of the operations, of the invariator, and of the absorptor.

Itelson (Berlin) : "Deduction, Induction, und Perduction."

The author spoke of the office of deduction and induction in mathematics. The inference from $n$ to $n+1$ is very improperly called complete induction; it consists of two reasonings, one complete induction and one deduction; on account of this it merits a special name. The speaker proposed the name perduction. 
Srmon (Strassburg): " Du continu, point, et ligne droite, remarques historiques."

The speaker referred to Galileo and Leonardo as the ones who had first recognized exactly the problem of the continuum ; he then proceeded to dispute the arithmetization of the continuum made by Cantor, pointing out that the fundamental series of Cantor defines an arithmetic segment. The speaker remarked that he agreed with Veronese. He then referred to the two axioms on continuity given by Hilbert, and declared that for geometric geometry they say nothing. He then spoke of points and lines, and concluded by declaring that he did not believe it possible to formulate with determinate propositions the mental labor which embraces periods of very long time.

Bernstein (Göttingen) : “ Nachweis, dass unter allen Beweisen des Pythagoräischen Lehrsatzes der Beweis des An-Nairizi (900 n. Chr.) der axiomatisch einfachste ist."

If we count as a criterion of simplicity the number of applications of the congruence axiom in the plane we have the precise result that a demonstration does not exist, for addition, which makes use of less than six applications. From this it follows that in the sense fixed, the demonstration of An-Nairisi (900 A. D.) is the simplest. This is an example of the method by which we can define the concept of simplicity of a demonstration, an example however which is not unique.

Pastore (Aosta) : "La natura extralogica delle leggi di tautologia e di assorbimento nella logica matematica."

The principal feature of this paper is the demonstration of the extralogical nature that is purely descriptive of the laws indicated. From such facts results the possible introduction in mathematical logic of a group of new notions and operations, among which the most noteworthy is that of multiples and powers universally rejected from Leibniz until the present time.

Lorra (Genoa) : "Le tradizioni matematiche dell'Italia."

This was the presidential address which Professor Loria delivered at the second session of the section. After greeting the members he gave the section a taste of the studies undertaken by him in order to continue the "Histoire des sciences mathematiques en Italie." Waiving the possibility that the history of Italian mathematics should begin with Pythagoras, Archimedes, and Archita, the author considers the beginning as 1200, 
when the "Liber abaci" of Leonardo Pisano appeared, to which he assigns much importance. He explained why Fibonacci had not had any immediate disciples by the fact that in the three succeeding centuries art absorbed the better minds; he touched lightly on the humanistic period and on the rising and flowering of mediaeval universities. He then said something of the golden period of Italian algebra, commenced with Luca Paciuolo and closed with Bombelli and Cataldi, noting how the discovery of the " punto di concorso" made by Guidobaldo del Monte opened a new era. The following century was that of Galileo Galilei, to whose school belong also Cavalieri, Torricelli, Borelli, and Viviani, to whom geometry owes so much. The author then passed to a description of the analytic works of Manfredi, Fagnani, and Ricatti, mentioning also G. Saccheri and G. Malfatti. In the century in which these flourished J. L. Lagrange was born. The speaker demonstrated that the latter should be counted as an Italian mathematician. He made mention also of Mozzi, Mascheroni, Ruffini, Fergola, Lorgna, and finally of the line of historians headed by Cossali. Passing to the nineteenth century, the speaker described the reception which descriptive geometry had in Italy, enumerating those who made it progress in Italy and was thus led to speak of the Italian geometric school founded by Luigi Cremona. That Italy was not a passive spectator of the development of analysis in the century preceding ours, is demonstrated by the schools which flourished at Turin, Pavia, and Pisa. In closing he made brief mention of the other illustrious mathematicians whose native land was Italy, noting that in no epoch were the Italian geometers isolated and that the history of Italian mathematics developed without interruption or lull; therefore there is hope that it will continue to flourish in the future.

ZEUTHeN (Kopenhagen): "Sur les rapports entre les principes anciens et modernes de la géométrie."

The author observed that each of the two groups of such principles is an inseparable logical system. In order to understand the ancient principles he considered their real point of departure. From this point of view he sought to show their logical value.

Smith (New York): "The Ganita-Sara Sangraha of Mahàviràcàrya."

Professor Smith recently visited Japan, China, and India for 
the purpose of procuring material illustrating the history of mathematics. In this paper he referred to the Indian treatise of the ninth century, of which Professor Rangacharya of Madras is preparing a translation which will be ready in two years. Mahàviràcàrya lived at Mysore about 850. His work is principally algebraic, but comprises also notions of arithmetic and of measure. The most interesting features of this treatise have reference to certain parts of a series, to special forms of nonrational equations and to indeterminate equations.

The publication of this work will be interesting for the history of mathematics tor the light which it will shed on the source of the works of Bhaskara, on the relation between the schools of Pataliputra and Ujjain and others of India, and on the influence of Greek mathematics on that of India and of this on that of Arabia.

Duhem (Bordeaux): "Sur la découverte de la loi de la chute des graves."

Professor Duhem called attention to the work of Albertus de Saxonia (De caelo et mundo) as that in which for the first time definite hypotheses were enunciated on the mode of variation of the velocity of falling bodies, and mentioned the possibility of the above work having influenced the ideas of Leonardo da Vinci.

GIACOMELLI (Rome): "I risultati di alcune ricerche sull'opera meccanica di Galileo."

The author showed the state of the historic questions on Newton's first two laws of motion, which, as is known, are due to Galileo. He showed what was the mental and experimental procedure used by Galileo to derive these laws. From the evidence it would result first that Galileo arrived at the proposition of the persistence of motion by making use of an idea already admitted by him a priori ; in the second place that those experiments on the inclined plane by which he is believed to have been led to the discovery of the law of inertia, rather led him to the discovery of the independence of motions ; finally that the relations between the two procedures were of purely external nature.

Pittarelli (Rome): "Luca Pacioli usurpò per se stesso qualche libro di Pièro de Franceschi ?"

The author made a minute comparative study between the 
Libellus Petri Pictoris Purgentis de quinque corporibus regularibus (copy existing at the Vatican) and Tractatus primus, secundus, tertius, which preceded the Divina proportione of Luca Pacioli and showed that these were indeed plagiarisms. He then gave a brief account of the Libellus from which it appears that Piero de Franceschi, artist, knew the geometry of Euclid quite well, and knew how to make use of algebra to solve geometric problems.

Gutzmer (Halle): “ ̈̈ber die Reformbestrebungen auf dem Gebiet des mathematischen Unterrichts in Deutschland."

The author gave a sketch of the work of the UnterrichtsKommission der Gesellschaft Deutscher Naturforscher und $\ddot{A}$ rzte, indicating the general lines of the project of reform of this commission, which was established after the Congress of Heidelberg and which has lately finished its labors.

Borel (Paris): "Les mathématiques dans l'enseignement secondaire en France."

Professor Borel began by showing how the secondary instruction in France is divided into various sections as shown in the following scheme:

First Cycle.

11-14 years.

$A$

$B$
Second Cycle.

$A$ Latin, Greek,

$B$ Latin, Modern Languages,

$C$ Latin, Sciences.

$D$ Science, Modern Languages.

In sections $A, B$ of the second cycle the instruction in mathematics is extremely reduced and for this reason the speaker dwelt only on the sections $C$ and $D$. He showed how some concepts had been introduced in these sections which before had been reserved for a later period, viz., the concept of the derivative as the slope of the tangent, and the notion of movement, concepts which Professor Borel holds are not more difficult than the comprehension of the Pythagorean theorem. He spoke also of the definition of cosine by means of the right triangle.

GODFREY (Winchester): "The teaching of mathematics in the English public schools for boys."

The author being absent, the paper was given in outline by President Vailati. 
Smith (New York): "The teaching of secondary mathematics in the United States."

The author explained that in this communication he had in mind the following purposes: 1) To put briefly in relief the historical influences which have contributed to the present state of mathematical studies in America ; 2) To make known the present conditions of mathematical instruction in the United States; 3) To call attention to the influence which is now operating to give new form to the secondary instruction ; 4) To consider some of the new directions ; 5) To suggest some questions which a section, as the present, might take into consideration with advantage in an international congress by means of the formation of a committee which should represent the principal nations interested.

This last point should be taken into consideration by those who shall have the care of preparing the program of the next congress, since the probable stimulating influence of an international committee on the betterment of mathematical instruction will be such as to justify the attempt.

Suppantschitsch (Vienna): “L'application des idées modernes à l'enseignement secondaire des mathématiques en Autriche."

It is necessary, according to the idea of Professor Suppantschitsch, to introduce into the secondary instruction the notions of function and derivative, establishing these in the first place without the notion of limit. In Austria experiments are actually in progress which will lead, without doubt, to a definitive rearrangement.

BEKE (Budapest): "Über den mathematischen Unterricht in Ungarn."

The Hungarian reforms are connected with those proposed by the German commission mentioned by Professor Gutzmer. A commission has also been appointed in Hungary which is occupied with the questions regarding instruction and which contemplates a reform in the instruction in mathematics by means of simplification of the programs and introduction of graphical exercises, by means also of the introduction of the concept of function and with a more intimate contact with practical applications, by means of the fusion of stereometry with descriptive geometry, and finally by means of the development of the sense of economy and with the introduction of the fundamental concepts of the differential and integral calculus. 
VAIlati (Rome) : "Su alcuni caratteri degli attuali programmi per l'insegnamento della matematica nelle scuole secondarie." Professor Vailati observed above all that, according to the present programs, the exercises on the solution of equations come too late in the instruction in algebra and that instruction in geometry is not put in intimate relation with the instruction in drawing. He also spoke of the utility of introducing the concept of the derivative into the instruction in the higher secondary schools.

Marcolongo (Naples): "Sopra un trattato inedito di meccanica di Vincenzo De Filippis anteriore alla Mécaniquę Analytique di Lagrange."

The author spoke of a mathematician of Calabria, minister of the "Republica Partenopea" in 1799, who died a victim of the Bourbon reaction at the end of that year.

De Filippis had prepared a treatise on mechanics which was certainly written before the Mécanique of Lagrange and which the author has been able to examine among the manuscripts which are still preserved by the heirs. He mentioned several noteworthy things about this treatise and signalized above all the fact that De Filippis had attempted a general demonstration, for rigid systems, of the principle of virtual work.

Stéphanos (Athens) : "Les mathématiques dans l'enseignement secondaire en Grèce."

After having traced in a few words the state of instruction from the capture of Constantinople to the epoch of the liberation of Greece, Professor Stéphanos spoke of the programs of mathematical instruction in Greece, and of the reform introduced in 1907 through the discussion and passage of a new law on text books.

Archenhold (Berlin): Über die Bedeutung des mathematischen Unterrichts im Freien in Verbindung mit Reformvorschlägen für den Lehrgang."

The mathematical conceptions should be deduced from observations of reality; this is exactly the principle of instruction. The different kind of angles should be presented by indicating the trees, considering houses, street crossings, etc. No problem should be solved without giving rigorous proof, but the concepts which are applied in the demonstrations must be acquired in 
principle by the use of real objects, not models. The simplest apparatus for measurement should find application at once to rectify the judgments, often fallacious, of the eye.

With such a method one can give in ten hours what otherwise would take years.

AxDRade (Besançon): "Quelques observations psychologiques recueillies dans les enseignements scientifiques d'initiation." Taking as example four very particular observed facts, Professor Andrade invoked a reform in the teaching of geometry, which he would reduce to two books : in the first the triangles, the dihedral, the trihedral ; in the second, similitude and measure of extension. He wishes thus to limit the study of geometry because of the very narrow field of secondary instruction, which general culture does not permit to subordinate to preparation in special mathematics, and recalls on this point the profound truth expressed by Marcello Prevost in the "Lettere a Francesca" which should be read and meditated upon by the students of the normal school.

Contr (Bologna): "Sulla iniziazione alle matematiche e sulla preparazione dei maestri elementari in Italia."

For the lowest grades, the Italian educational legislation is still quite embryonic, without special instructions defining the limits, the programs, and the methods. If we desire that the primary grade does not prejudice the subsequent work of the school, it is necessary that that grade itself be disciplined in a manner that will serve for rational preparation for education and instruction.

The reforms tending to introduce in secondary instruction some mathematical concepts until now deferred, must be accompanied by others for these primary grades and for the elementary schools, in such a manner that the totality of the things taught in this first stage be a rational beginning for the subsequent studies.

One commits an exaggeration and falls into an equivocation when he opposes the statement that some special attitude for the assimilation of the most elementary concepts of mathematics is present in all pupils.

A rational beginning must be inspired by the general principles, defended by Froebel, Pestalozzi, Herbart, Chalotais, Vittorino da Feltre, and particularly by the mathematicians, by the 
principles on the basis of which Laisant recently republished his golden "Initiation mathématique." To such principles must the teachers of all grades of elementary schools be devoted. The children are now oppressed by a true and proper study; they are now required to do an annoying amount of memorizing, and are fettered by a continual formalism.

The actual arrangement of the normal school, the brevity of the course, the insufficiency of time assigned to mathematics, the defects of the present programs in rigor, and the imperfect functioning of the novitiate, all show that the mathematical preparation of elementary teachers is not adequate to the delicacy and importance of the mission which is confided to them. Therefore it is to be hoped that the rearrangement of the normal schools, imposed by the law of July 8, 1904, will not longer be delayed.

Fenr (Geneva): "Les mathématiques dans l'enseignement secondaire en Suisse."

After giving a summary of the organization of the higher secondary instruction in Switzerland, Professor Fehr showed the place which mathematics occupies, principally in the classic and technical sections. It is to be observed that in the classical gymnasia four hours per week is given to mathematics, in all classes, and that there for a long time trigonometry, plane and spherical, and analytic geometry have had a place, and consequently also notions of simple functions. In the technical sections of the gymnasia all branches of mathematics treated in the classical sections are studied more thoroughly, and also descriptive geometry and the elements of the differential and integral calculus are taught.

Garcia de Galdeano Zoel (Saragoza): "Alcune notizie sull'insegnamento matematico in Spagna."

The political struggle in Spain has retarded the progress of science and impeded the application of a new arrangement of public instruction. Nevertheless the founding of the Spanish scientific society, whose first act will be the mathematical congress of Saragoza next September, will be the beginning of a new scientific epoch. The speaker lamented that the elementary part of Spanish university instruction causes the higher instruction to be lost. He closed by making mention of the pedagogical means which, in his opinion, are the best 
for establishing an equilibrium between the progress of science and the intellectual potentiality for the study of science itself; these means he has defended in his publication, Alcunas consideraciones sobre filosofia y enseñanza de la matematica, of which many copies were kindly offered to the congress.

GallucCr (Naples) : “ La questione logica e gnoscologica nei fondamenti della matematica."

The critique of the principles of mathematics belongs to mathematics and philosophy : whence a double point of view in their treatment; the logical point of view and the gnoscological point of view. The author gave a summary of the consequences of such a twofold view and mentioned as a possible conclusion that it might lead to a reelaboration of the theory of knowledge in which account is taken of the latest developments of the principles of science.

Broggi (Rome): "Sui fondamenti del calcolo delle probabilità."

The author proposed a new descriptive definition (of the third kind) of the concept of probability and demonstrated the compatibility and the irreducibility of the system of postulates assumed to define probability.

Емсн (Solothurn): "Der Rechenkünstler Winkler und seine Methoden."

One of the most interesting personalities in the field of the art of calculating is Johann Jacob Winkler. While in various memoirs much is said of other calculators one finds almost nothing of Winkler; it is the purpose of this paper to tell something of this marvelous man, who was born February 23, 1831, in Wernatswill and died August 25, 1893, at the canton hospital of Stanz, poor and abandoned.

Winkler easily solved mentally every problem which presented itself in calculable form and utilized also all the rules of rapid calculation which can be deduced from algebraic formulas.

LoRIA (Genoa): "Sur les moyens pour faciliter et diriger les études sur l'histoire des mathématiques."

Professor Loria, taking the cue from a recent article by Professor Eneström, noted that there are some persons who would be disposed to cultivate the history of mathematics if 
they should find some one who would guide them over the not easy road; and he noted how, the beginning of courses being difficult "ad hoc," the best system which presents itself is the compilation of a manual for researches in the history of mathematics, collective works whose plan would be determined conveniently enough by an international congress. In order to prepare the way for discussion, the author indicated the various subjects which, according to him, should find place in the work planned. He closed by presenting to the section one of his plans of an Indice delle materie.

Amodeo (Naples) : "Appunti su Biagio Pelicani da Parma."

The author quoted from M. Cantor on the importance of knowing the content of the only known treatise published by Biagio da Parma, except for a very rare collection of mathematical treatises published at Vienna in 1515 ; and said that having had this collection in hand he has found in it two treatises of Biagio da Parma, and another treatise of Giovanni de Casali hitherto unknown.

From the reading of these two treatises of Biagio da Parma, he has found that his name should be written Pelicani instead of Pelacani, and that in Bologna this man had a dispute on the impact of rigid bodies which forms the subject of the treatise now found.

He gave an outline of the contents of the treatise entitled Tractatus de latitudinibus formarum Blasii de Parma, and concluded that in it the conception of Nicole Oresme on the latitude of the plane geometric form was enlarged and complicated by Biagio Pelicani by deviating from the straight road which would have enabled him to arrive sooner at the conception of the analytical geometry of Descartes, and that in this he was soon followed by his contemporaries, contributing to the putting aside of the simplicity of the question as it had been conceived by Oresme.

Pittarelli (Rome): "Due lettere inedite di Lagrange all" Abate di Caluso esistenti nell' archivio storico municipale di Asti."

Professor Pittarelli found the letters in the Archive of Asti and now presents them (photographed for the occasion and given to the congress by the municipality of Asti). He was happy to give them into the hands of the two presidents, Professor Picard 
and Professor Simon, one from France and the other from Germany, nations which Lagrange, known and having become celebrated at Turin, rendered illustrious with his name in return for the hospitality which he had there. He asked that of the two copies one remain at the $R$. Accademia dei Lincei and the other with the faculty of science of the University of Rome.

Amodeo (Naples) : "Sulla necessità di formare un archivio delle scienze matematiche."

In view of the difficulty of determining the author of a new proposition the historians of the science are often misled into assigning incorrect origins. The author emphasized the necessity of removing this difficulty, and urged the formation of a general scheme of archives of mathematical sciences. A detailed plan was submitted for adoption, but the section concluded that the congress should not yet undertake the enormous labor ; it affirmed however the convenience of establishing such archives.

De Amrcis (Brescia): "L'equivalenza (in planimetria) independentemente dalle proporzioni e dal circolo."

Considering substantially only the equivalence of parallelograms of equal bases and altitudes, the author established the theorem : If a triangle has its angles equal to those of a second triangle, the rectangle formed by a side of one and a side of the other is equivalent to the rectangle formed by the corresponding sides, independently of proportion and of the properties of the circle, without making use of the theorem on homothetic triangles.

Brouwer (Amsterdam) : " Die möglichen Mächtigkeiten."

Seeking principally how it would be possible to construct a mathematical system, the author demonstrated that it can not be possible for more than three infinite powers to exist, viz., the enumerable, the incomplete enumerable, and the continuum.

Delitala ( ) : "La tetragonometria piana nelle scuole secondarie."

It was proposed to reunite and complete some results which the author had already published on tetragonometry. He gives the fundamental problems in the following terms. Given 5 of the 18 elements of the plane tetragon, of which at least one is a side, find the remaining 13 elements. 
This contains within itself the enunciation of many problems in elementary geodesy. He asks if one should not seek to introduce by elementary methods this geometry into the secondary schools.

C. L. E. Moore.

\section{NOTES.}

The July number (volume 9, number 3 ) of the Transactions of the American Mathematical Society contains the following papers: "Brilliant points of curves and surfaces," by W. H. Roever; "Continuous increasing functions of finite and transfinite ordinals," by O. VeBLEN ; "Projective differential geometry of curved surfaces (third memoir)," by E. J. WILCZYNSKI ; "Invariants of the function $F\left(x, y, x^{\prime}, y^{\prime}\right)$ in the calculus of variations,", by A. L. UNDERHILL; "The integration of a sequence of functions and its application to iterated integrals," by R. G. D. Richardson.

THe July number (volume 30, number 3) of the American Journal of Mathematics contains the following papers: "Determination of conjugate points for discontinuous solutions," by O. BoLzA; "Mathematical logic as based on the theory of types," by B. Russell ; "Invariantive reduction of quadratic forms in the $G F\left[2^{n}\right]$," by L. E. DICKson ; "The motion of a particle attracted toward a fixed center by a force varying inversely as the fifth power of the distance," by W. D. MACMrlllan.

THE concluding (July) number of volume 9 of the Annals of Mathematics contains the following papers: "On the spherical representation of a surface," by P. SAUREL; “The absolute minimum in the problem of the surface of revolution of minimum area," by Miss M. E. SinclaIR ; "Note on the roots of Bessel functions," by C. N. Moore ; "A smooth closed curve composed of rectilinear segments with vertex points which are nowhere dense," by E. R. HEDRICK ; "Evaluation of the probability integral," by F. GILMAN ; "On a second theorem of the mean," by C. N. HASKINs ; "Another proof of a theorem in multiply perfect members," by R. D. CARMichaEL; "A theorem concerning equal ratios," by J. L. Coolidge ; "Note on certain iterated and multiple integrals," by W. A. Hurwitz. 